\title{
Pembuatan Service Level Requirement, Service Level Agreement dan Operational Level Agreement pada Layanan Help Desk SAP Berdasarkan Kerangka Kerja ITIL Versi 2011 (Studi Kasus : Pupuk Indonesia Holding Company)
}

\author{
Nur Shabrina Prameswari, Tony Dwi Susanto \\ Jurusan Sistem Informasi, Fakultas Teknologi Informasi, Institut Teknologi Sepuluh Nopember (ITS) \\ Jl.Arief Rahman Hakim, Surabaya 60111 Indonesia \\ e-mail: tonydwisusanto@is.its.ac.id, nurshabrinap@gmail.com
}

\begin{abstract}
Abstrak-PT. Pupuk Indonesia Holding Company baru saja melakukan implementasi SAP pada tahun 2014. Dalam penerapannya, perusahaan merasa perlu membuat help desk SAP sebagai pusat penanganan masalah bagi perusahaan dan 7 anak perusahaannya yang kemudian dapat berfungsi juga sebagai knowledge base yang berguna apabila ada masalah yang berulang di waktu selanjutnya. Untuk merancang layanan help desk yang baik, perlu didefinisikannya target layanan dalam sebuah kontrak perjanjian antara pengguna layanan dan penyedia layanan. Selain itu, perjanjian layanan tersebut diperlukan juga sebagai jaminan kualitas help desk yang dapat disepakati oleh penyedia layanan dan pengguna layanan yang merupakan pengguna SAP pada PT. Pupuk Indonesia dan anak perusahaannya. Hal tersebut bertujuan untuk menyelaraskan bisnis dengan kualitas layanan serta menentukan kebutuhan dan harapan pelanggan dalam sebuah perjanjian antara penyedia layanan dan pengguna layanan. Dari permasalahan tersebut, maka diperlukan pembuatan dokumen Service Level Requirement, Service Level Agreement dan juga Operational Level Agreement pada help desk SAP, dengan dilakukan observasi dokumen dan wawancara pada pihak pengguna layanan dan penyedia layanan, maka setelah itu dibuatlah dokumen Service Level management tersebut berdasarkan ITIL Versi 2011.
\end{abstract}

Kata Kunci-ITIL Versi 2011, Layanan Help Desk, Operational Level Agreement (OLA), Service Level Agreement (SLA), Service Level Requirement (SLR),

\section{PENDAHULUAN}

$\mathrm{P}$ UPUK Indonesia merupakan salah satu perusahaan produsen pupuk terbesar di Asia, yang baru saja melaksanakan restrukturisasi holding pada tahun 2011. Dalam rangka melakukan integrasi data dengan 7 anak perusahaannya, PT. Pupuk Indonesia kemudian melakukan implementasi SAP yang dimulai tahun 2014. Seiring dengan proses implementasi SAP, tidak sedikit laporan yang timbul mengenai permasalahan penggunaan SAP dan PT. Pupuk Indonesia perlu untuk mendokumentasikannya.

Pupuk Indonesia membutuhkan dasar pengetahuan terlebih dahulu untuk menyelesaikan masalah yang ada terkait dengan SAP. Sehingga, untuk mengantisipasi masalah yang sulit diselesaikan, Pupuk Indonesia membutuhkan sistem help desk, yang kemudian berfungsi untuk menghasilkan knowledge base apabila terdapat masalah yang berulang. Help desk merupakan penyedia layanan yang baik terkait request fullfilment, incident management, problem management serta access management, help desk juga bertanggung jawab untuk memastikan bahwa semua keluhan dari konsumen dapat diselesaikan secara tepat waktu sesuai dengan perjanjian tanpa harus kehilangan tiket (help desk ticket) keluhan tertentu [1].

Dalam menyelesaikan suatu keluhan atau permintaan layanan, tentunya diperlukan Kepastian kualitas layanan yang sesuai dengan tingkat layanan yang telah disepakati dengan pelanggan merupakan salah satu aspek penting dalam penerapan manajemen layanan teknologi informasi. Hal tersebut digambarkan pada level Service Design di ITIL pada proses Service Level Management. Service Level Management adalah sebuah proses yang bertujuan untuk menyelaraskan bisnis dengan kualitas layanan serta menentukan kebutuhan dan harapan pelanggan dalam sebuah perjanjian antara penyedia layanan dan pengguna layanan. Service Level Management memiliki beberapa keluaran, diantaranya Service Level Requirement (SLR), Service Level Agreement (SLA) dan Operational Level Agreement (OLA) [2]. Ketiga dokumen tersebut perlu dibuat untuk menjelaskan kebutuhan layanan, ketersediaan layanan, performa layanan serta peran dan tanggung jawab internal support penyedia layanan pada perusahaan. PT. Pupuk Indonesia memerlukan ketiga dokumen tersebut untuk mendefinisikan layanan kepada pengguna layanannya yaitu pengguna SAP pada internal PT. Pupuk Indonesia sendiri maupun 7 anak perusahaan Pupuk Indonesia serta untuk mendefinisikan kesepakatan mengenai pembagian kerja didalam internal penyedia layanan untuk melakukan support apabila ada pelaporan permasalahan ataupun permintaan layanan pada help desk.

\section{URAIAN PENELITIAN}

\section{A. Tahap Persiapan}

Tahap persiapan merupakan tahap awal dalam melakukan penelitian ini. Aktivitas yang dilakukan pada tahap ini yaitu 
menyusun Interview Protocol untuk Preliminary Data help desk SAP, kemudian melakukan Preliminary Data Gathering yaitu melakukan wawancara pada pihak penyedia layanan untuk mendapatkan data dan informasi umum terkait help desk SAP yang disediakan, selain itu Preliminary Data Gathering juga bertujuan untuk mendapatkan dokumen perusahaan terkait help desk sebagai pendukung penelitian ini. Aktivitas selanjutnya yaitu penyusunan interview protocol untuk pembuatan dokumen SLR, SLA dan juga OLA berdasarkan standar acuan yaitu ITIL versi 2011, serta berdasarkan hasil preliminary data gathering yang telah didapatkan.

\section{B. Tahap Pembuatan SLR}

Setelah tahap persiapan, tahap selanjutnya yaitu pembuatan dokumen Service Level Requirement (SLR). Dalam membuat dokumen SLR, diperlukan aktivitas sebagai berikut yaitu, penggalian data dan informasi terkait SLR help desk SAP melalu review dokumen yang telah didapatkan pada tahap persiapan dan juga dilakukan wawancara pada pihak pengguna layanan. Setelah didapatkan data dan informasi terkait dokumen SLR, kemudian diperlukan adanya verifikasi data dan informasi SLR help desk SAP untuk menyamakan persepsi dan pendapat antara penulis dengan narasumber terkait. Aktivitas selanjutnya yaitu pembuatan dokumen SLR help desk SAP yang dimulai dengan identifikasi dan analisa hasil wawancara, baru kemudian dilakukan verifikasi dan validasi dokumen SLR help desk SAP.

\section{Tahap Pembuatan SLA}

Setelah dilakukan verifikasi dan validasi dokumen SLR, maka baru dimulai tahap yang selanjutnya yaitu pembuatan dokumen Service Level Agreement (SLA). Dalam membuat SLA, diperlukan aktivitas sebagai berikut yaitu, penggalian data dan informasi terkait SLA help desk SAP berupa review dokumen dan wawancara pada penyedia layanan yang mengacu pada standaracuan ITIL versi 2011 dan dokumen SLR yang telah divalidasi, kemudian diperlukan adanya verifikasi data dan informasi SLA help desk SAP untuk menyamakan persepsi dan pendapat dengan narasumber, selanjutnya yaitu pembuatan dokumen SLA help desk SAP serta melakukan verifikasi dan validasi dokumen SLA help desk SAP.

\section{Tahap Pembuatan OLA}

Dokumen yang terakhir dibuat yaitu dokumen Operational Level Agreement (OLA) setelah Dokumen SLA selesai diverifikasi dan divalidasi. Dalam membuat OLA, diperlukan aktivitas sebagai berikut yaitu, yang pertama penggalian data dan informasi terkait OLA help desk SAP berupa review dokumen dan wawancara, kemudian diperlukan adanya verifikasi data dan informasi OLA help desk SAP untuk menyamakan persepsi dan pendapat, selanjutnya pembuatan dokumen OLA help desk SAP serta melakukan verifikasi dan validasi dokumen OLA help desk SAP.

\section{E. Tahap Akhir}

Tahap ini merupakan tahap terakhir dalam penelitian tugas akhir ini. Dalam tahap ini, penulis melakukan penyusunan dokumen akhir yang berupa dokumen SLR, SLA dan OLA yang telah terverifikasi dan tervalidasi dengan melakukan penarikan kesimpulan yang didokumentasikan dalam buku tugas akhir.

\section{HASIL DAN PEMBAHASAN}

\section{A. Penyusunan SLR}

Dalam penyusunan dokumen SLR, dilakukan identifikasi job desk help desk SAP yang didapatkan dari wawancara dan juga review dokumen, selain itu dilakukan identifikasi kebutuhan layanan seperti daftar layanan dan juga kategorisasi layanan. Dari hasil identifikasi, didapatkan layanan yang telah dikelompokan sesuai kategorinya seperti berikut:

Tabel 1.

Daftar layanan terkategorisasi

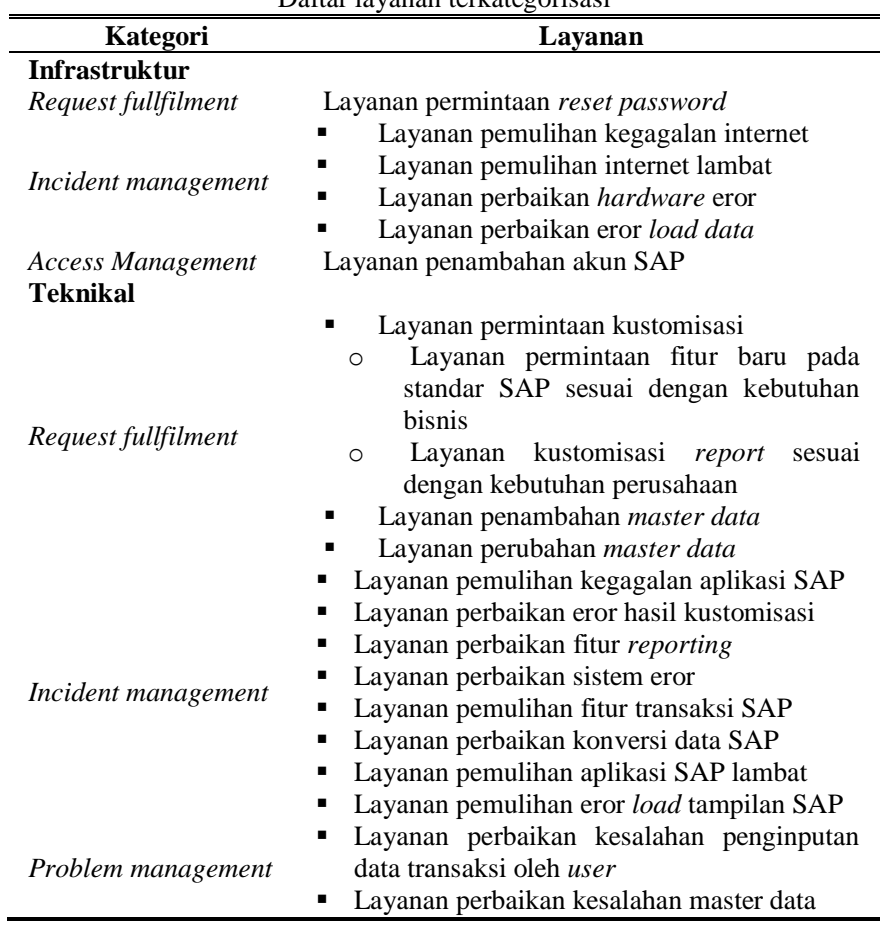

Pada penyusunan dokumen SLR, juga dilakukan identifikasi daftar layanan dan waktu penanganan layanan sesuai aspek yang diharapkan oleh pengguna layanan.

Berdasarkan checklist SLR ITIL versi 2011 yang disesuaikan dengan kebutuhan perusahaan, didapatkan struktur dan konten dokumen SLR sebagai berikut [4]:

Tabel 2.

Struktur dan konten dokumen SLR

\begin{tabular}{ccc}
\hline \hline Struktur Bab & Sub-bab & Konten \\
\hline Informasi Umum & Pihak terkait & $\begin{array}{c}\text { Uraian informasi pihak } \\
\text { pengguna layanan dan } \\
\text { penyedia layanan }\end{array}$ \\
& Nama Layanan & \\
& Deskripsi Layanan & \\
Indikator Kesuksesan & \\
Pengguna Layanan & Bersifat Deskriptif \\
Teskripsi Layanan & Layanan & \\
& Tanggal berakhir & \\
& layanan & \\
\hline \hline
\end{tabular}




\begin{tabular}{ccc}
\hline \hline & $\begin{array}{c}\text { Deskripsi Kelompok } \\
\text { Layanan }\end{array}$ & $\begin{array}{c}\text { Uraian Daftar layanan } \\
\text { beserta target layanan } \\
\text { Uraian ketersediaan } \\
\text { waktu layanan dan } \\
\text { waktu penanganan } \\
\text { layanan }\end{array}$ \\
Klossary & Ketersediaan help desk & $\begin{array}{c}\text { Uraian definisi istilah- } \\
\text { istilah yang digunakan }\end{array}$ \\
\hline \hline
\end{tabular}

\section{B. Penyusunan SLA}

Pada proses penyusunan dokumen SLA, dilakukan identifikasi daftar layanan berdasarkan dokumen SLR. Setelah dilakukan wawancara, didapati bahwa terdapat perubahan daftar layanan disertai penghapusan layanan dan juga penambahan layanan. Layanan yang dihapuskan yaitu Layanan perbaikan hardware eror, sedangkan layanan yang ditambahkan yaitu Layanan Role Authorization dan Layanan penambahan field text dan input pada form SAP.

Kemudian, berdasarkan checklist SLR ITIL yang disesuaikan dengan kebutuhan perusahaan, didapatkan struktur dan konten dokumen SLA sebagai berikut [3]:

Tabel 3.

Struktur dan Konten dokumen SLA

\begin{tabular}{|c|c|c|}
\hline Struktur Bab & Sub-bab & Konten \\
\hline Informasi Umum & Informasi Pihak terkait & $\begin{array}{c}\text { Uraian informasi pihak } \\
\text { pengguna layanan dan } \\
\text { penyedia layanan }\end{array}$ \\
\hline & Nama Layanan & \\
\hline Deskripsi Layanan & $\begin{array}{l}\text { Deskripsi Layanan } \\
\text { Tanggal dimulai } \\
\text { Layanan } \\
\text { Tanggal berakhir } \\
\text { layanan }\end{array}$ & Bersifat Deskriptif \\
\hline $\begin{array}{l}\text { Layanan yang } \\
\text { ditawarkan }\end{array}$ & $\begin{array}{l}\text { Layanan Infrastruktur } \\
\text { Layanan Teknikal }\end{array}$ & $\begin{array}{l}\text { Deskripsi tiap-tiap } \\
\text { layanan help desk }\end{array}$ \\
\hline \multirow{8}{*}{$\begin{array}{l}\text { Komunikasi antara } \\
\text { pelanggan dan } \\
\text { penyedia layanan }\end{array}$} & $\begin{array}{l}\text { Kontak personal } \\
\text { pelanggan }\end{array}$ & $\begin{array}{l}\text { Uraian informasi } \\
\text { kontak personal } \\
\text { pengguna layanan }\end{array}$ \\
\hline & $\begin{array}{l}\text { Kontak personal } \\
\text { penyedia layanan }\end{array}$ & $\begin{array}{l}\text { Uraian informasi } \\
\text { kontak personal } \\
\text { penyedia layanan } \\
\text { Uraian ketentuan }\end{array}$ \\
\hline & Pelaporan layanan & $\begin{array}{c}\text { pelaporan layanan help } \\
\text { desk }\end{array}$ \\
\hline & $\begin{array}{l}\text { Status Keluhan dan } \\
\text { permintaan layanan }\end{array}$ & $\begin{array}{c}\text { Uraian status tiket help } \\
\text { desk }\end{array}$ \\
\hline & $\begin{array}{l}\text { Prosedur penanganan } \\
\text { keluhan dan } \\
\text { permintaan layanan }\end{array}$ & $\begin{array}{c}\text { Uraian prosedur } \\
\text { penanganan tiket help } \\
\text { desk }\end{array}$ \\
\hline & Eskalasi & $\begin{array}{c}\text { Uraian eskalasi help } \\
\text { desk }\end{array}$ \\
\hline & Help desk Channel & $\begin{array}{c}\text { Uraian jalur } \\
\text { komunikasi help desk }\end{array}$ \\
\hline & $\begin{array}{l}\text { Review layanan help } \\
\text { desk }\end{array}$ & $\begin{array}{c}\text { Uraian review layanan } \\
\text { help desk }\end{array}$ \\
\hline Keamanan TI & $\begin{array}{c}\text { Keamanan TI help } \\
\text { desk }\end{array}$ & $\begin{array}{c}\text { Uraian keamanan TI } \\
\text { help desk }\end{array}$ \\
\hline Waktu layanan & $\begin{array}{l}\text { Waktu pelayanan } \\
\text { standar }\end{array}$ & $\begin{array}{c}\text { Uraian waktu } \\
\text { pelayanan help desk }\end{array}$ \\
\hline waktu layanan & Waktu penanganan & $\begin{array}{c}\text { dan waktu penanganan } \\
\text { keluhan }\end{array}$ \\
\hline Required Types and & Infrastruktur & $\begin{array}{l}\text { Uraian infrastruktur } \\
\text { yang didukung oleh } \\
\text { help desk }\end{array}$ \\
\hline & $\begin{array}{l}\text { Pengguna Layanan } \\
\text { help desk }\end{array}$ & $\begin{array}{l}\text { Uraian pengguna } \\
\text { layanan help desk }\end{array}$ \\
\hline $\begin{array}{l}\text { Service Level } \\
\text { Agreement }\end{array}$ & $\begin{array}{c}\text { Deskripsi Kelompok } \\
\text { Layanan }\end{array}$ & $\begin{array}{l}\text { Uraian Daftar layanan } \\
\text { beserta target layanan }\end{array}$ \\
\hline
\end{tabular}

\begin{tabular}{ccc}
\hline \hline Standar Teknis & $\begin{array}{c}\text { Standar teknis help } \\
\text { desk }\end{array}$ & $\begin{array}{c}\text { Uraian spesifikasi } \\
\text { teknisi layanan help } \\
\text { desk }\end{array}$ \\
Glossary & Daftar Istilah & $\begin{array}{c}\text { Uraian definisi istilah- } \\
\text { istilah yang digunakan }\end{array}$ \\
\hline \hline
\end{tabular}

Konten dari dokumen SLA didapatkan dari hasil wawancara dengan penyedia layanan yang mengacu pada dokumen SLR yang kemudian disesuaikan dengan kemampuan penyedia layanan. Selain perubahan layanan dari dokumen SLR ke dokumen SLA, didapatkan beberapa perubahan terkait dengan target layanan dan waktu layanan yang disediakan.

\section{Penyusunan OLA}

Pada penyusunan dokumen OLA, data dan informasi didapatkan dari hasil wawancara dengan pihak teknisi penyedia layanan. Struktur dan Konten dari dokumen OLA hampir sama dengan dokumen OLA, hanya saja terdapat tambahan satu bab yaitu bab Operational Level Agremeent. Bab tersebut berisi mengenai ketersediaan layanan dan kapasitas yang disesuaikan dengan kemampuan pihak teknisi help desk. Berikut merupakan hasil perubahan dari dokumen SLA ke dokumen OLA.

- Pada target layanan, ketersediaan layanan pada jam kerja ditambahkan waktu 30 menit setelah pulang operasional jam kerja. Kemudian untuk kapasitas layanan per harinya ditambah dengan 1 permintaan untuk setiap layanan untuk berjaga.

- Target Waktu penanganan layanan dikurangi sebanyak 2 jam dari waktu yang disediakan di dokumen SLA untuk berjaga.

\section{KESIMPULAN/RINGKASAN}

Dari hasil penelitian yang telah diperoleh, dilakukan penarikan kesimpulan mengenai pembuatan dokumen SLR, SLA dan OLA pada layanan help desk SAP di Pupuk Indonesia. Terdapat tiga rumusan masalah yang dapat disimpulkan berdasarkan hasil penelitian yang telah dilakukan, yaitu sebagai berikut:

1. Hasil observasi dokumen dan wawancara terkait Service Level Management help desk SAP

Dari hasil observasi dokumen yang dilakukan, didapatkan dokumen dari perusahaan yaitu dokumen ICT Master Plan Pupuk Indonesia termasuk dokumen Tata Kelola IT Pupuk Indonesia, serta Dokumen Project Charter implementasi SAP Pupuk Indonesia. Kemudian diperlukan observasi dokumen standar acuan penelitian ini yaitu ITIL versi 2011. Pada dokumen standar acuan yang digunakan yaitu ITIL, didapatkan konsep dan checklist penyusunan dokumen Service Level Management yaitu mulai dari dokumen SLR, SLA dan juga OLA pada Service Design. Selain itu pada Service Operation didapatkan konsep mengenai help desk dan juga jaminan layanan help desk terkait Availability, Capacity, Continuity dan Capacity. Sedangkan dokumen yang didapatkan dari perusahaan yaitu Dokumen ICT Master Plan berisi tentang kebijakan yang harus dipatuhi mengenai help desk seperti job deskripsi help desk termasuk lingkup hingga prioritas penanggulangan permasalahan TI pada perusahaan. Dan juga didapatkan dokumen Project Charter yang berisi Stakeholder 
proyek SAP, struktur organisasi dan juga tupoksi yang diberkaitan dengan penyusunan help desk SAP.

Selain dilakukan observasi dokumen, dilakukan wawancara pada pengguna layanan dan penyedia layanan. Wawancara pada pengguna layanan dilakukan untuk menyusun dokumen SLR, sedangkan wawancara pada penyedia layanan dilakukan untuk menyusun dokumen SLA dan juga OLA. Dari wawancara yang telah dilakukan, didapatkan beberapa poin penting untuk menyusun dokumen, diantaranya yaitu, ruang lingkup help desk SAP, Struktur manajemen help desk SAP, rincian eskalasi help desk SAP serta tugas, pokok dan fungsi dari masing-masing peran yang terkait dalam tim help desk SAP. Selain itu, untuk penyusunan dokumen SLR, dilakukan penggalian kebutuhan layanan help desk termasuk kebutuhan layanan apa saja yang diharapkan agar tersedia, kebutuhan ketersediaan layanan help desk dan juga kebutuhan target layanan. Untuk menyusun dokumen SLA, didapatkan data dan informasi terkait komunikasi antar pengguna dan penyedia layanan, keamanan IT help desk, waktu layanan dan target layanan help desk yang dapat disediakan oleh tim help desk. Kemudian untuk menyusun dokumen OLA, dilakukan penggalian data terkait kemampuan teknisi untuk menyediakan layanan dengan ketersediaan layanan dan kapasitas layanan yang telah ditentukan.

2. Pembuatan dokumen Service Level Requirement, Service Level Agreemet dan Operational Level Agreement

Dari hasil observasi dokumen dan wawancara, dilakukan identifikasi dan analisa untuk pembuatan dokumen. Untuk pembuatan dokumen SLR, dilakukan identifikasi job desk help desk SAP, identifikasi kebutuhan layanan termasuk daftar layanan dan pengkategorian layanan. Selain itu, diperlukan aktivitas identifikasi tabel daftar layanan dan identifikasi waktu penanganan layanan help desk. Dalam penyusunan dokumen, tentunya diperlukan susunan struktur dokumen yang mengacu standar acuan dan disesuaikan dengan kebutuhan perusahaan. Maka, didapatkan struktur dokumen SLR yang terdiri dari Informasi umum, deskripsi layanan dan juga layanan help desk yang berupa deskripsi kelompok layanan dan ketersediaan help desk.

Dalam penyusunan dokumen SLA, diperlukan identifikasi daftar layanan dari pengguna layanan yang kemudian disesuaikan dengan kemampuan penyedia layanan. Kemudian dilakukan penyusunan struktur dokumen berdasarkan standar acuan dan disesuaikan dengan kebutuhan layanan, sehingga terbentuklah struktur dokumen SLA yaitu Informasi umum, Deskripsi layanan, Layanan yang ditawarkan, Komunikasi antara pengguna dan penyedia layanan yang menjelaskan tentang pelaporan layanan, prosedur penanganan permintaan dan keluhan, eskalasi dan juga channel help desk. Selain itu terdapat informasi keamanan TI, waktu layanan, deskripsi infrastruktur yang dilibatkan, pengguna layanan help desk, deskripsi kelompok layanan dan juga standar teknis help desk SAP.

Kemudian untuk penyusunan dokumen OLA, dilakukan identifikasi perubahan dari dokumen SLA ke OLA. Dengan struktur dokumen yang sama antara SLA dan OLA, perbedaanya yaitu terdapat daftar kelompok layanan Operational Level Agreement dan terdapat waktu layanan yang berbeda karena telah disesuaikan dengan ketersediaan teknisi help desk SAP.
3. Hasil verifikasi dan validasi dokumen Service Level Management pada help desk SAP

Pengujian Dokumen SLR, SLA dan OLA dilakukan dengan dua cara, yaitu dengan melakukan verifikasi dan validasi. Verifikasi bertujuan untuk memastikan bahwa dokumen SLR, SLA dan OLA yang disusun telah sesuai dengan kebutuhan organisasi. Verifikasi dilakukan dengan wawancara langsung kepada pihak pengguna dan penyedia layanan. Selanjutnya dilakukan validasi yang bertujuan untuk menguji ketepatan dokumen yang telah disusun. Validasi dilakukan dengan cara checklist dari dokumen yang telah disusun. Dari uji verifikasi yang telah dilakukan terdapat beberapa perbaikan diantaranya pada dokumen SLR yaitu penambahan aspek level dampak pada prioritasi penanganan keluhan dan permintaan layanan. Aspek tersebut adalah vendor dan pihak eksternal yang terkait. Dari hasil verifikasi SLA, juga didapatkan beberapa perbaikan yaitu perbaikan daftar layanan yaitu pengurangan layanan perbaikan hardware eror yang dinilai sebagai tanggung jawab lokal perusahaan masing-masing. Selain itu juga terdapat perubahan waktu respon pada dokumen SLA. Kemudian dari hasil verifikasi OLA, didapatkan bahwa konten dari dokumen OLA telah sesuai dengan kebutuhan perusahaan.

Hasil validasi dari dokumen SLR, SLA dan OLA juga terdapat perubahan minor, pada dokumen SLA yaitu kesalahan penulisan nomor telepon help desk dan juga kesalahan tata huruf yang harus diperbaiki pada bagian daftar layanan.

\section{UCAPAN TERIMA KASIH}

Penulis menyampaikan terima kasih sebesar-besarnya kepada semua pihak yang telah mendukung, mengarahkan, memberi semangat dalam menyelesaikan penelitian ini, yaitu kepada :

- Allah SWT yang atas berkat dan rahmat-Nya penulis dapat menyelesaikan penelitian ini.

- Almarhumah Diah Ayu Mayuchasari Aghda, seorang sahabat yang membuat penulis bersemangat melanjutkan penelitian yang dahulu dimulai bersama pada saat kerja praktik di Jakarta.

- Orang tua penulis dan adik-adik penulis. Bapak penulis, Ir. Arief Prapsoedi,MM, Ibu penulis, Alvira Dhiany yang selalu mendoakan penulis, dan juga kepada adik-adik penulis Yasmin Ambar Pratiwi dan Abimanyu Bagus Prasetyo.

- Bapak Tony Dwi Susanto, S.T,M.T,P.hd,ITIL selaku guru, satu-satunya dosen pembimbing penulis sekaligus motivator penulis untuk selalu produktif dan tidak pernah berhenti belajar dan belajar.

- Ibu Anisah Herdayanti S.Kom,M.Sc yang selalu bersedia meluangkan waktunya untuk membimbing penelitian ini.

- Bapak Dr. Apol Pribadi, S.ST, MT dan Ibu Feby Artwodini, S.Kom, MT selaku dosen penguji penulis yang turut membimbing, memberikan kritik dan saran dalam pengerjaan penelitian ini sehingga dapat diselesaikan dengan baik.

- Bapak Mardiyanto selaku manajer IT, Bapak Mgs. Prima selaku manajer PSDM PT. Pupuk Indonesia persero yang turut membantu penulis dalam pengerjaan penelitian ini. 
- Bagus Wahyu Utomo, S.Kom, seorang sahabat, kawan, lawan, teman berkeluh kesah, dan seorang yang penulis anggap sebagai pembimbing eksternal setia penelitian ini.

- Sahabat sholehah, Archita Arinta, S.Kom, Inayatin Ulya, S.Kom, Rahma Permatasari, Rizqi Amalia yang menjadi penyemangat hari-hari penulis. Bersama-sama saling mendorong saat motivasi rendah.

- Seluruh pihak yang ikut mendukung dan membantu pengerjaan penelitian ini.

\section{DAFTAR PUSTAKA}

[1] I. Middleton, "Key Factors in Help desk Success (An analysis of areas critical to help desk development and functionality.)," British Library R\&D Report 6247, 1996.

[2] L. Hennebeck, ITIL Service Design 2011 Edition, 2011.

[3] "Cheklist SLA and OLA," Wiki ITIL, [Online]. Available: http://wiki.en.it-processmaps.com/index.php/Checklist_SLA_OLA. [Diakses September 2015].

[4] "Checklist Service Level Requirement," Wiki ITIL, [Online]. Available: http://wiki.en.it-processmaps.com/index.php/ Checklist_Service_Level_Requirements_(SLR). [Diakses October 2015]. 